\title{
Exploring a Loan Translation and Its Consequences in an Oral Bilingual Corpus
}

\author{
Barbara E. Bullock \\ Professor of French Linguistics, Department of French and Italian, \\ University of Texas at Austin, Austin, USA \\ bbullock@austin.utexas.edu \\ Jacqueline Serigos \\ Assistant Professor of Spanish Linguistics, Department of Modern and \\ Classical Languages, George Mason University, Fairfax, USA \\ jserigos@gmu.edu \\ Almeida Jacqueline Toribio \\ Professor of Spanish Linguistics, Department of Spanish and Portuguese, \\ University of Texas at Austin, Austin, USA \\ toribio@austin.utexas.edu
}

\begin{abstract}
This work applies computational tools that have been used to model loanwords in newspaper corpora to an analysis of a loan translation in an oral bilingual corpus. The explicit goal of the contribution is to argue that a specific collocation found in a corpus of Spanish spoken in Texas, agarrar+NP (e.g., agarrar ayuda), is a loan translation that is calqued on English get+NP support verb constructions (e.g., get help). We base our argument on the frequency and the linguistic distribution of the nonconventional usage within and between corpora and on the factors that favor its use. Our findings show that the overall frequency of agarrar is the same in Spanish in Texas as it is in the benchmark monolingual corpus of Mexican Spanish but that it is used differently in the two varieties, a difference that has grammatical, as well as semantic, ramifications.
\end{abstract}

\section{Keywords}

calques - loan translation - frequency - pattern replication - corpus - Spanish English 
This article undertakes an analysis of a particular construction in a minority language, Spanish, that has been in long-term contact with the majority language, English, in the American southwestern state of Texas. In particular, we investigate the possibility that the unconventional use of Spanish agarrar, meaning 'to grab' or 'to grasp' as a lexical verb, occurs as a calque of English 'to get' in loan translations that parallel the meaning of frequent English collocations such as to get a job. On the one hand, the construction that we examine, agarrar $+\mathrm{NP}$, has been argued to be the result of influence from English (Sayer, 2008). But it has also been claimed to be an outcome of an internal change, an extension of the meaning of agarrar in vernacular Mexican Spanish used by monolinguals as well as bilinguals in Texas (Sánchez, 1972, 1982). In an attempt to resolve this issue and to contribute more generally to methodologies for exploring contact phenomena, we compare the frequency of occurrence of agarrar+NP in a 500,000-word open corpus of oral Spanish spoken in Texas (Bullock and Toribio, 2012; Toribio and Bullock, 2016) against its occurrence in monolingual corpora, including the oral section of the Corpus del Español (Davies, 2002), and the Mexican, Argentine, and Spain movie subtitles of the ACTIV-eS corpus (Francom et al., 2014, 2010). We then compare its use in specific expressions with an oral Mexican corpus, exploring the possibility that this loan translation is a type of light or support verb construction in which the nominalized base selects a semantically general verb as a collocate.

In their seminal contribution on loan translations, Backus and Dorleijn (2009) remark that loan translations (or calques), like agarrar+NP, merit closer scrutiny than they have received in the contact literature because they tend to occur in tandem with code-switching (Cs) in corpora (although see Poplack, Zentz, and Dion, 2012 for a view of the distribution of cs and convergence as complementary). The authors define a loan translation as "any usage of morphemes in Language A that is the result of the literal translation of one or more elements in a semantically equivalent expression in Language B" (Backus and Dorleijn, 2009: 77). The key example they offer is a contact Turkish verb+object collocation similar to the one we examine in Spanish-English contact: a Dutch expression piano spelen piano to $_{\mathrm{N}} \mathrm{play}_{\mathrm{V}}$ is calqued as the Turkish expression piano oynamak in place of conventional Turkish, piano çalmak piano ${ }_{\mathrm{N}}$ to sound, That is, Turkish oynamak is used as a literal translation for Dutch 
spelen just as agarrar is putatively used as a calque of English get. Examples of verb+object constructions such as these are readily available in many bilingual corpora and they appear to be prevalent in learner corpora, where transfer is less controversially assumed to be the source of expressions that are congruent with the source language (Laufer and Waldman, 2011).

Backus and Dorlejn are motivated in their study of loan translations by the question of why bilingual speakers might choose to translate a given expression from the source language into the recipient language rather than import the source language morphemes wholesale by code-switching. They speculate that the semantic specificity of an expression in the source language may lie at the root of the choice to switch, while the frequency of the expression in the source language might provoke loan translation instead. Whether or not this can be borne out empirically remains to be seen, but they submit, correctly in our opinion, that an accountable model of bilingual behavior should attend to the factors that induce bilinguals to choose one option over the other. In order to even begin to test whether there are indeed factors that might lead one to use a loan translation versus a code-switch to express a particular construction, there is a need to find a method to accurately identify loan translations in a corpus, since unconventional structures arise in minority-language contexts for reasons other than transfer. In fact, it might be fair to say that with data from speakers in contact settings, only Cs, where overt morphemes are transferred from a source to a recipient language, is uncontroversially accepted as a sign of language interaction among contact linguists. Even the classification of a lone lexical borrowing as a contact-induced feature can be debatable if its usage is diffused to speakers with no knowledge of the source language. And many experienced contact linguists treat claims of semantic or structural transfer with extreme skepticism because it can rarely be ruled out that the feature in question could not be plausibly explained as an internally-motivated variation (e.g., semantic extension/analogy of a minor syntactic pattern) or, alternatively, that it might be attested in a non-contact or pre-contact variety of the recipient language that has not been consulted (Poplack, Zentz, and Dion, 2012; Poplack and Levey, 2010). To resolve doubts about the origin of a form in a contact variety, it is common practice in contact linguistics to evaluate the form against a series of proofs, which include the inspection of multiple corpora for the presence/absence of a structure or of linguistically similar structures.

Different heuristics for classifying a change as contact-induced have been proposed in contact linguistics. These can be roughly categorized along three planes: criteria of linguistic similarity, of distribution across corpora, and of degree of contact (Thomason, 2001; Mougeon, Nadasdi, and Rehner, 2005; 
Poplack and Levey, 2010; Treffers-Daller, 2011). The test of linguistic similarity requires that there be a feature in the recipient language that manifests similar properties to the source language and that the feature at issue be unconventional for the recipient language. We should underline here that linguistic similarity is currently defined qualitatively in sociolinguistics. In a second test, the distribution of the feature at issue should be consulted in corpora besides the one under study, including corpora of monolingual recipient language speakers and corpora of monolingual source language speakers (Poplack, Zentz and Dion, 2012). Ideally, corpus comparison is frequency-based and, thus, constitutes a quantitative test, but since bilingual varieties are low-resource languages in corpus linguistics, it is not always the case that the relevant data can be summoned for a robust comparison (Sitaram and Black, 2016). The last criterion, degree of contact, arises from work in sociolinguistics with speakers of different levels of bilingualism (Dubois and Noetzel, 2005; Mougeon et al., 2005). It is recommended that the probability of occurrence of the feature be examined as a function of the degree of contact or bilingualism within the population.

Whereas much of the empirical work in corpus-based approaches to contact has been conducted in the variationist sociolinguistic tradition of Labov (1972), Treffers-Daller (2011) advocates for a frequency-based comparative approach to transfer in her study of the effect of Dutch on Brussels French particle verb constructions. Her method is founded on comparing the probability that an unconventional construction appears in the contact corpus relative to non-contact corpora. While the methodologies of corpus linguistics and variationist sociolinguistics differ, there is agreement among practitioners in both camps that comparing corpora qualitatively for the presence vs. absence of a feature is insufficient to confirm and/or reject a contact-based source. In brief, these scholars agree that it is not possible to debate the role of transfer when considering only isolated examples. What is needed are quantitative analyses.

In what follows, we combine variationist and frequency-based approaches in the study of the agarrar+NP construction as it appears in Spanish in Texas as compared to other corpora. We conduct an analysis of the frequency of agarrar in the bilingual Texas corpus and in various monolingual Spanish corpora, followed by an analysis of the complements of agarrar in Spanish and Texas compared to its source variety, oral Mexican Spanish. Then, we adopt the Cognitive Sociolinguistic approach of Zenner et al. (2012), in which the use of a loanword is compared to the use of its native language competitor, in carrying out a multifactorial analysis in the investigation of the frequency of agarrar relative to other lexical contenders. We examine the consequences of innovative agarrar+NP construction on the grammar of this contact Spanish variety, pursuing the following research questions: 
1. Is the use of the verb agarrar increased in general in the bilingual corpus as compared to other Spanish varieties?

2. Is agarrar + NP used in a qualitatively similar manner in bilingual versus in a predominantly monolingual corpus?

3. What linguistic and external factors predict the use of agarrar $+\mathrm{NP}$ expressions relative to alternatives in the bilingual corpus?

The organization of our work is as follows. In Section 2, we overview the previous literature on the specific construction under study and argue that it shares crucial properties with the support verb constructions that occur in English with the verb to get. In Section 3, we explain our methodology, including a brief introduction to the Spanish in Texas Corpus Project (Bullock and Toribio, 2012; Toribio and Bullock, 2016). We present our results in Section 4 and discuss them in Section 5 , focusing on the insight they offer with respect to our research questions. We conclude in section 6 with some reflections about the implications of our findings for studies in loan translation and for methodologies in quantitative work on contact in the future.

\section{The Case of agarrar+NP in American Varieties of Spanish}

In its most canonical use, the Spanish verb agarrar is lexical and transitive, denoting the sense of grasping, grabbing, clutching, or seizing a physical object, such as an animal, a hand, a book, etc. In this typical case, the subject of the verb is agentive, as in the example (1a). In a secondary vernacular usage, in (1b), the verb reflects the sense of being seized by something abstract, often a malady. The grammatical subject in this latter case, which usually appears post-verbally, is non-agentive and the object is the affected theme or patient. Of interest here is what appears to be an innovative usage found in U.S. Spanish in which the subject of agarrar is thematically an experiencer or beneficiary and the object is an abstract theme, as in (1c): agarro un segundo aire '(I) get a second wind'.

(1) Canonical uses of agarrar as a lexical verb
a. Agarré
el
volante
grab:1SG;PST
ART;DEF;M
steering_wheel
'I grabbed the steering wheel.'
b. $M e$
1SG;ACC
'The flu got me.'
agarró
get:3SG;PST
la
gripe

ART;DEF;F flu




$\begin{array}{llll}\text { c. } & \text { Agarro } & \text { segundo } & \text { aire } \\ \text { get:1SG;PRS } & \text { ART;INDF;M } & \text { second:M } & \text { air } \\ \text { 'I got a second wind.' } & & \end{array}$

In a seminal description on the Spanish spoken in the American southwest, Sánchez (1994: 11) observes examples similar to (1c) and attributes the usage of the verb agarrar in Chicano Spanish to the fact that, like its counterpart in English, get, it is used in frequent collocations and, as such, it is part of "general knowledge" within a community:

All languages also have ready-made expressions of high frequency that can communicate as much as more complex structures, which may be considered unnecessary in informal contexts. In English, for example, there are numerous expressions containing the verb get. It is thus nothing strange that informal Spanish has a number of similar expressions containing the verb agarrar. These expressions, common in many Spanish speaking nations and thus not unique to Southwest Spanish, are quite frequent in Chicano communities.

As an illustration of these "ready-made" expressions, consider the examples in (2), culled from the Spanish in Texas Corpus. Each Spanish example is listed with its similar English expression, followed by the canonical alternative verb that would normally select that complement in Spanish-speaking regions outside the Southwest. Note that items (f) and (g) are linguistically mixed forms, using the Spanish verb and an English complement.

(2) Examples of unconventional agarrar+NP expressions with their English equivalent
a. agarrar becas
'get scholarships' (cf., recibir, obtener, ganar)
b. agarrar trabajo
'get work'
(cf., conseguir)
c. agarrar experiencia
'get experience'
(cf., obtener)
d. agarrar buenas notas
(cf., sacar)
e. agarrar crédito
'get good grades'
(cf., recibir, obtener)
f. agarrar Most Shy
'get credit'
(cf., ganar)
g. agarrar mi Bachelor's
'get Most Shy'
(cf., obtener)
e. agarrar ayuda
'get my Bachelor's'
'get help'
(cf., obtener, conseguir) 
What the expressions in (2) all seem to share is the notion that the subject is the recipient or beneficiary of an abstract attainment (e.g., an award, a job). As the core sense of agarrar as a lexical verb is that of physical grasping, it is clear that the verb in these constructions is not used in its literal sense, that this is qualitatively different from others. Instead, agarrar here appears to take on the more generalized sense of its English equivalent to get, which is normally expressed in Spanish via other verbs: obtener, recibir, conseguir, sacar, ganar.

Sánchez's argument that the extended usage of agarrar ensues from community knowledge is similar to that of Otheguy (1993) in highlighting shared cultural norms, likely made salient by frequency of occurrence. Otheguy contends that the term loan translation in reference to such usage among U.S. Spanish speakers is a "flawed construct" that "contributes to mistaking as Anglicization of their language what is simply the Americanization of their culture" (Otheguy, 1993: 21). The crux of Otheguy's argument is that calques, presumably no matter how frequent, do not alter the grammar of Spanish in any qualitative way. Thus, he interprets them as semantic extensions within specific phrases or as markers of a community's assimilation to U.S. norms. For these scholars, then, loan translations in U.S. Spanish are signs of cultural contact rather than the consequences of speakers' establishing linguistic similarity between English and Spanish. An additional sign that agarrar expressions pass the notice of U.S. Spanish speakers themselves is that the contact linguist, Silva-Corvalán fails to remark upon the construction agarrar trabajo (cf., conseguir, obtener trabajo) 'to get work', which appears in a citation that illustrates the semantic extension of the another verb, descansar 'to rest' to mean lay off (from a job)' (Silva-Corvalán, 1994: 185).

Sayer (2008: 103) also refers to the use of agarrar as a semantic extension and notes that it is impossible to directly discern from decontextualized examples if an individual's extended use of the verb is idiosyncratic or conventionalized as part of the community norm. In other words, we cannot tell from examining examples such as those in (2) whether the individual who uttered them calqued them on the spot or simply acquired them. However, Sayer is not prepared to concede that the extended use of agarrar is as conventional outside the U.S. Southwest as Sánchez asserts it is, mentioning in a footnote that Spanish speakers from Mexico rejected the examples he collected, considering them to be tokens of "pocho" (i.e., rotten, Americanized) Spanish. A similar reluctance is presented by Cárdenas (1982: 39) who states of his data from Southern California that "the overuse of agarrar in U.S. Spanish is reinforced by the interference of its English counterpart", referring to frequent get expressions. 
Semantic extension (or semantic shift) is a common (monolingual) language-internal process whereby words take on new meanings as a reflection of social change. For instance, in many varieties, the Spanish word niñera has shifted in meaning from 'nanny' to include that of 'babysitter'. Semantic shift reflects a type of lexical change whose effect on grammar is anodyne. But Backus and Dorleijn (2009) take pains to make clear that loan translations comprise a change in the meaning of lexical items as they are used in specific expressions, where the line between lexical change and structural change is blurred. In this respect, loan translations result in a type of lexical innovation that can introduce new constructions in a language and not just additional denotations (Wasserscheidt, 2016). The fact that agarrar is appearing with complements that generally occur in constructions with different verbs in varieties of Spanish outside the context of the U.S. and the Mexican border is the very reason that Sayers and Sánchez comment on its broadened semantics. In other words, the extension in the meaning of agarrar is unlike that of niñera. It does not pick out different actions in the real world as referents. Instead, it is via its co-occurrence with a particular complement that a shift of meaning of agarrar is accomplished. That is, the extended meaning is due to the complement; the verb itself has lost its core meaning. In this respect, the agarrar+NP expressions are similar to light verb constructions.

\subsection{Light or Support Verb Constructions}

The term 'light verb', originally coined by Jespersen (1954), refers to a verb in a complex predicate that loses most, but not all, of its semantic value, and is accompanied by a nominal or verbal complement that provides the majority of the semantic content, e.g., have a rest (=rest), take a breath (=breathe), get a ride (=ride). In many light verb constructions, the meaning of the collocation is often redundant with the meaning of the noun (e.g., get access (to) = access). Such constructions are also known as support verb constructions (svc) (Mel'čuk, 2004). Mel'čuk (2012) defines these as consisting of a freely chosen semantic base and a collocate that depends upon it. While some svC s are more idiomatic than others - consider the relatively transparent get advice vs. the figurative get the sack - they share certain universal characteristics (Wierzbicka, 1982). As one example, the noun generally appears in the indefinite and the collocate supplies the verbal inflections and specifies the relations of the arguments of the predicate noun. However, while the light verb is semantically general, it is not always the case that it is meaningless (Butt, 2010). Salido (2016:364) provides cases from Spanish in which the support verb clearly imparts the contrast in valency between the subject of hacer llamada 'make a call' and coger/tomar llamada 'take a call'. 
Support verb constructions are attested in numerous languages (Butt, 2004) and the topic of light verbs is frequently addressed from a bilingual perspective, but most often with regard to bilingual compound verbs (BCV). BCVs appear across language pairings, ostensibly to facilitate the borrowing of verbs. Generally, they comprise a de-verbalized noun from the source language and a recipient language light verb, usually to do or to make (Romaine, 1986). For instance, in the Spanish-English me haces email si pudiste hacer view el documento ('email me if you were able to view the document') Spanish contributes the light verb hacer ('to do'), which carries the requisite morphology, and English provides the semantic content (email, view) for the verbal compounds. The literature on code-switching is rich with theoretical and qualitative analyses devoted to BCVs (Romaine, 1986; Muysken, 2000; Edwards and GardnerChloros, 2007).

Less well studied are the verb $+\mathrm{N}$ loan translation collocations that are the subject of the present work. These do not involve the use of overt lexemes of other language material, rather the meaning (and combination) of a specific expression. Copying the meaning and form from one language to another results in a literal translation, which can be of the svc type. The study of support verb constructions is a concern not only in minority language settings (Backus and Dorleijn, 20o9; Otheguy, 1993) but also in the domain of second language acquisition and pedagogical materials design since the accurate selection of the collocate verb can be difficult for learners and is very often subject to interlingual transfer, even among advanced language learners (Salido, 2016). In a study of verb+NP collocation errors made by Hebrewspeaking learners of English, Laufer and Waldman (2011) found that nearly $90 \%(42 / 47)$ of the error types in svCs that persisted from basic to advanced levels of L2 proficiency were direct translations of their semantically equivalent Hebrew collocations.

\subsection{The Status of English get and Spanish Agarrar as Support Verb}

The support verbs in svcs are among the most frequently used verbs in a language because they can semantically select a wide range of complements. For instance, in English make, get, give, do, take, and have are most frequently used in such constructions (Biber et al., 1999); of interest here is, of course, get. Molina Plaza (2015) presents a contrastive analysis of svCs with get (and take) in English and their equivalents in Spanish, languages where support verb constructions are said to be semi-productive (Wierzbicka, 1982; Kearns, 2002). To do so, she examines the most frequent English collocations with get in the British National Corpus (BNC) and their Spanish equivalents in the CREA (Corpus de Real Academia Española). Her results show that the 
most frequent collocations of English to get combine overwhelmingly with an abstract noun, "referring to treatment or a service given to a person or to a thing on behalf of a person [...]; a second category refers to an office or power given to a person, such as access, admittance, appointment, authority, award and a last small category refer to a process being begun such as (get an ache), (get into an) argument" (Molina Plaza, 2015: 187). Analyzing the CREA equivalents of frequent English constructions (e.g., get access), Molina Plaza finds the use of full lexical verbs in Spanish (e.g, acceder), Spanish nouns (e.g., el acceso) and Spanish support verb constructions primarily using the usual \{get\} equivalents: obtener, conseguir, and tener. She does not mention agarrar as a svC equivalent for any of the English get constructions she encounters in CREA. Olsen (2014) undertakes a qualitative analysis of the use of agarrar as a support verb in the Corpus del Español (Davies, 2002), which includes data from American and European varieties of Spanish. She reports that the most common NP complements for agarrar are concrete and/or animate, consistent with its denotation of grabbing or grasping a physical object or being. She also classifies four different uses of agarrar as a support verb when it does not signify grasping. These include its co-occurrence with complements that denote maladies, emotional states, abstract notions that are used to express activities (i.e., seizing a concept), and appearances. While Olsen acknowledges the appearance of agarrar with abstract complements, her analysis includes no quantification, so the extent to which they occur in the Corpus del Español is unknown.

In sum, there are linguistic reasons that would lead one to suspect that the agarrar $+\mathrm{NP}$ constructions in (2) are calqued on similar English get $+\mathrm{NP}$ expressions. In the first case, the grammatical structure parallels the English light verb use in that the noun commonly appears in the indefinite; in Spanish, this is manifested by the use of bare nouns. In addition, the verb agarrar has lost its core lexical meaning and acquired a general sense that parallels the bleached semantics of English get. Finally, as is the case for English get as a light verb, agarrar regularly appears as a collocate with an abstract complement. In the following study, we attempt to quantitatively examine the frequency and distribution of agarrar in our contact corpus relative to a non-contact Spanish oral corpora to bolster this analysis.

The current study utilizes tokens gathered from the Spanish in Texas Corpus (Bullock and Toribio, 2012; Toribio and Bullock, 2016) in multifactorial logistic 
models. Additionally, the ACTIV-ES corpus, comprising Argentine, Mexican, and Spanish subtitles from movies (Francom, Hulden, and Ussishkin, 2014; Francom, LaCross, and Ussishkin, 2010), the Corpus del Español (Davies, 2002), and the English SubtlexUS (Brysbaert and New, 2009) serve as comparison monolingual corpora for tests of frequency. This section describes the corpora along with the processing protocol, which involves both manual and automated methods.

\subsection{Corpora}

The Spanish in Texas Corpus (Bullock and Toribio, 2012; Toribio and Bullock, 2016) contains nearly 500,000 words from 97 interviews conducted primarily in Spanish in survey regions representing major metropolitan areas: El Paso (EP) at the state's western border with Mexico; the Central Region (CR), including the capital city, Austin, and the large metropolitan areas of Dallas-Fort Worth; the Rio Grande Valley (VA) on the southern border with Mexico, and the city of San Antonio (SA). The corpus was created between the years of 2010-2012 with the assistance of Spanish-English bilingual interviewers (ages 18-35) who recruited members of their social networks to participate in interviews. There were multiple interviewers for each survey point, with the exception of El Paso, where one interviewer collected all of the interviews $(n=12)$. This is because El Paso is located at the western extreme of Texas, approximately $900 \mathrm{~km}$ from the next closest survey point ( $\mathrm{SA}$ ).

All interviewees answered an extensive linguistic history questionnaire, so this corpus contains metadata about each speaker's country of birth, current city of residence, self-reported language use in Spanish, Spanish language proficiency in reading, writing, and listening, and information on parents' educational, linguistic, and national background. Most of the individuals interviewed were from Mexico or the U.S., but there was no restriction placed on country of origin so that the corpus includes speakers from Argentina, Colombia, El Salvador, Uruguay, Venezuela, Spain, Peru and South Korea. A Mixing Index (Barnett et al., 200o) was calculated for each speaker to provide a ratio of the word count of English to Spanish used in the interview. The M-index values were consistently very low, with Spanish providing the overwhelming majority of tokens across the corpus and within each speaker-interviewer dyad. The size of our corpus situates it between the 1.5 million-word corpus collected from 141 speakers of Spanish in New York (Otheguy and Zentella, 2012) and the 120,000word bilingual corpus of Spanish-English speech from New Mexico (TorresCacoullos and Travis, 2013), each of which have been profitably exploited to study variation in U.S. Spanish. Unlike the New York and the New Mexico corpora, the Spanish in Texas Corpus is an open resource, downloadable in 
text version via its web portal: https://spanishintexas.org. The source for the Spanish spoken in Texas is predominantly that of its neighbor, vernacular Mexican Spanish.

The oral section of the Corpus del Español (Davies, 2002), at the time of its consultation, comprised data from 2,040 sub-corpora, including informal speech and Mexican Spanish, for a total word count of 5,113,249. The data in the Corpus del Español is accessible through a query-based web interface. Because this Corpus includes oral samples from various performance registers of speakers throughout the Spanish-speaking world with limited metadata, it is not useful as a monolingual comparison corpus for vernacular Mexican Spanish, but we include it here as a follow-up to Olsen (2014) who consulted it for support verb constructions with agarrar.

The ACTIV-es corpus comprises subtitles from Argentine, Mexican and Spanish movies, resulting in 3.4 million words, with a near even distribution across the three regions: Argentina: 1,232,656; Mexico: 1,107,057; Spain: 1,557,521 (Francom et al., 2014). Although this corpus represents scripted speech, Francom et al. (2010) tested the lexical validity of the corpus for each region on speakers from each country using a 'Frequency Effects' design in which speakers judge their familiarity with a visually presented word from their language. The lexical behavior of native speakers from each of the three populations correlates significantly with lexical content (frequency and dispersion of words) in their respective sub-corpora, and not with that in the other sub-corpora. These results suggest that "at the word level, lexical variation found in the ACTIV-ES corpus approximates particular usage patterns of the respective native populations and provide support for the representativeness of these sub-corpora" (Francom et al., 2014: 1737). We consider the Mexican subcorpus of ACTIV-ES to represent our monolingual, non-contact source variety.

The token count of English \{get\} was obtained from the subtitle corpus of U.S. films and television, Subtlex-US, for the purposes of establishing an English monolingual baseline (Brysbaert and New, 2009). The validity of the English subtitle corpus for reflecting lexical frequency in the U.S. was successfully tested by the authors of that corpus.

\subsection{Processing Methods}

To find all instances of agarrar in the Spanish in Texas Corpus and in ACTIV-ES, a Python script written by the present authors was used to gather all forms of the verb along with the accompanying metadata. The metadata included speaker information for the Spanish in Texas Corpus and individual movie information in ACTIV-ES. The script extracts the verb and a surrounding 20-word context window. It also automatically identifies the tense and person 
of each token through a rule-based method. The tokens from the Spanish in Texas Corpus and the Mexican sub-corpus in ACTIV-ES were manually annotated by the authors for details about the complement, including whether it is a pronoun or a lexical noun, whether it is abstract or concrete (person or physical object), and whether the experiencer is the direct object of the verb or not. For the bilingual corpus, each realization of a semantic competitor of agarrar was coded in the same way, notably adquirir 'to acquire', coger 'to take', conseguir 'to obtain, attain', aprender 'to learn, realize', obtener 'obtain', recibir 'to receive', sacar 'to get', and tomar 'to take'. In total, 330 verb+NP collocations were annotated for Spanish in Texas.

The data were modeled to compare the frequency of agarrar across Spanish corpora and to analyze the predictive factors for the selection of agarrar versus its competitors in the Spanish in Texas Corpus. To do this, the frequency of agarrar was calculated for each corpus and these frequencies were compared to ascertain the likelihood that the tokens were pulled from the same distribution. Multifactorial logistic models were fit to the data from the Spanish in Texas Corpus to predict the occurrence of the use of agarrar relative to its semantic competitors. The models were fit with the linguistic factors of the person and tense of the verb, whether the complement was a pronoun or noun, whether the complement was abstract or concrete, and whether the verb was used reflexively. The external predictor variables included age, gender, survey region of Texas, M-index value, self-ratings on a 5-point Likert scale of Spanish language use, and of speaking, listening, reading, and writing ability in Spanish.

The oral section of the Corpus del Español was queried for the token count of agarrar through the Graphical User Interface (GUI) provided by the portal. The data from the Corpus del Español, the ACTIV-es Spain, and the ACTIV-ES Argentina are analyzed for token count.

TABLE 1 Token counts and of \{agarrar $\}$ and English $\{$ get $\}$ across corpora

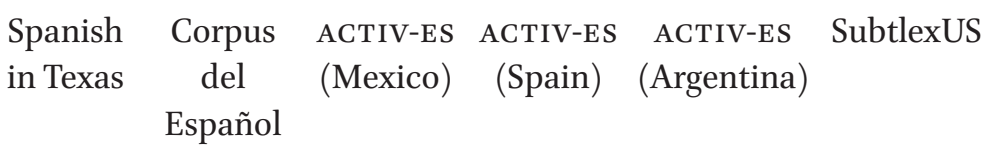

$\begin{array}{lrrrrrr}\begin{array}{l}\text { Word } \\ \text { count }\end{array} & 502,329 & 5,113,249 & 960,589 & 1,380,924 & 1,103,037 & 5 \text { o,ooo,ooo } \\ \begin{array}{l}\text { agarrar\} } \\ \text { per }\end{array} & 103 & 220 & 208 & 40 & 143 & 416,535 \\ \text { million } & 205 & 43 & 217 & 29 & 130 & 8,167 \\ & & & & & & \end{array}$




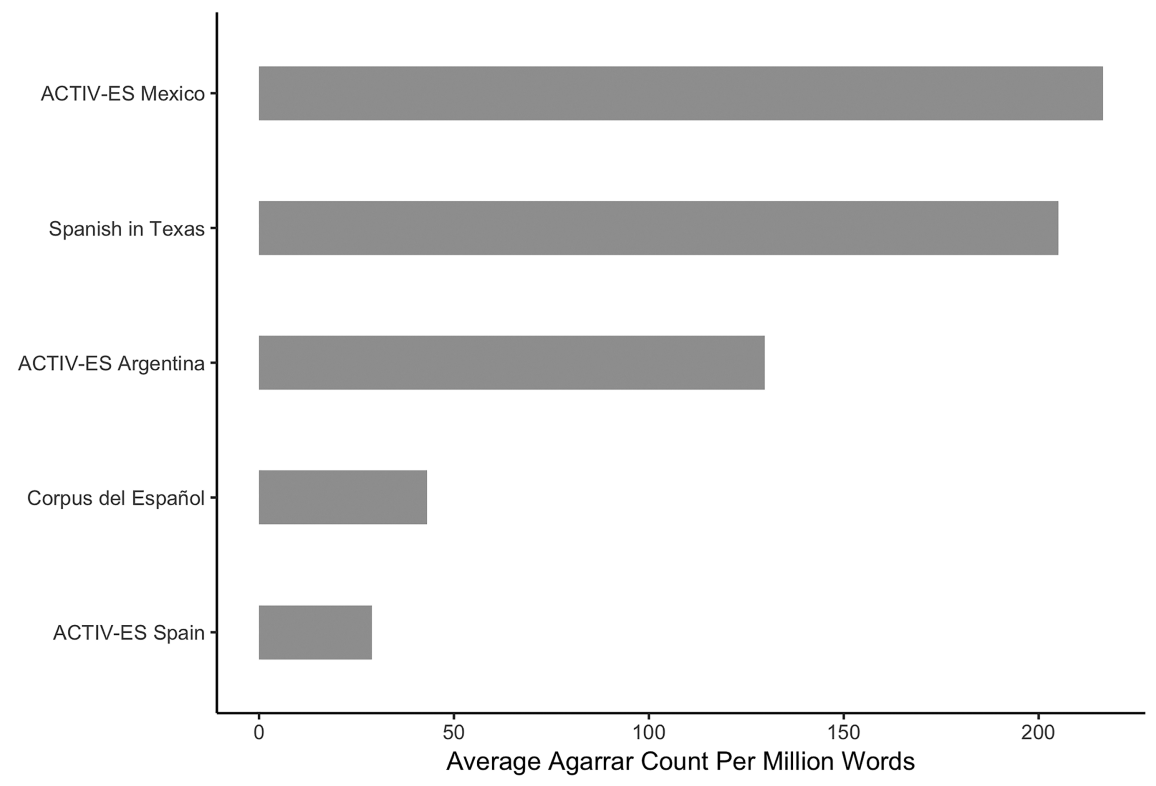

FIGURE 1 Rate of \{agarrar\} per million words across oral Spanish corpora

Results

The descriptive results of the frequency of the \{agarrar\} lemma in the various oral Spanish corpora are shown in Table 1 relative to the counts for the English lemma \{get\} in the monolingual oral sub-corpora. Of note is the high frequency of the English verb \{get\} relative to the low frequency of Spanish \{agarrar\}.

The rates of agarrar usage, normalized per million, in the Spanish in Texas Corpus compared to the monolingual Spanish corpora are visualized in Fig. 1. Texas and (ACTIV-ES) Mexico have the highest rates of agarrar usage, around 200 tokens per million. Argentina follows, using agarrar around 35\% less than Texas and Mexico. Spain and the Corpus del Español both present over $80 \%$ fewer tokens of this verb than Texas and Mexico.

To test the significance of the differences between the \{agarrar\} frequencies depicted in Fig. 1, a Pearson's Chi-square test, without Yates correction was calculated and found to be highly significant $(X$-squared $=495 \cdot 4813, \mathrm{df}=4$, $p$-value $<2.2 \mathrm{e}-16)$. The Chi-square test is commonly used for word frequency comparisons in corpus linguistics. However, it is sensitive to sample size: as sample size increases, the $p$-value decreases (see Coe, 2002; Kilgarriff, 2001) Thus for large corpora, such as those employed in this study, statistical significance may not reflect a true difference but simply the size of the sample. To account for this sensitivity, we computed the effect size, which factors out 


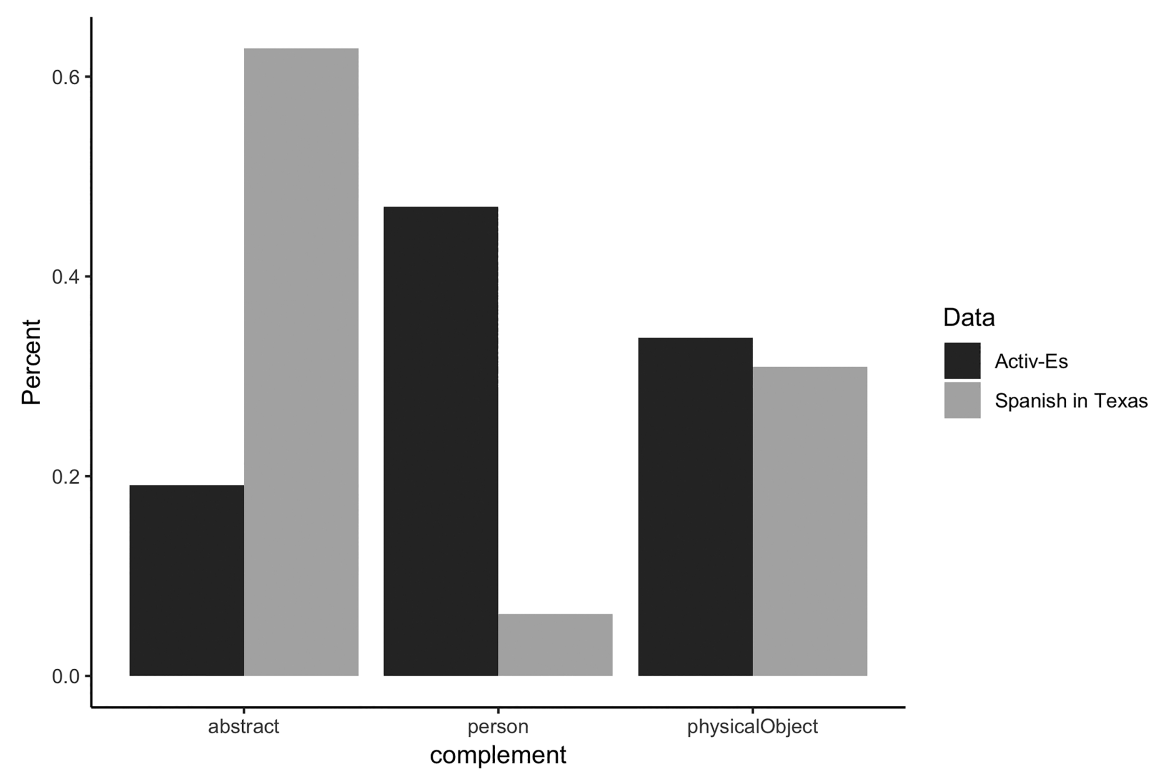

FIGURE 2 Complement category distribution across corpora

the size of the sample and reveals the magnitude of the association between the variables of interest. Applied to our data, a test of association queries the probability that randomly selecting a token of \{agarrar\} from one corpus would be the same as selecting it from another. To do this, we employed the Cramér's V test, following Cohen (2013), which yielded a value of .007, indicating a very weak association. We also checked for effect size using a common language effect size, which is meant to be a more intuitive measure of effect size than Cramér's V test (Coe, 2002). The value was 50.34\%, indicating that probability is basically at chance. These measures of effect size imply that the presence of the verb agarrar is not necessarily increased in general in bilingual Spanish as compared to other Spanish varieties. While the Argentine and Peninsular varieties do show much lower usage of agarrar, the non-contact variety of Mexican Spanish shows similar usage of agarrar to the contact variety of Spanish in Texas. And due to the variation expected in large corpora, none of the differences show a strong association with their respective corpus.

While the Texas and Mexico corpora show agarrar with similar frequencies, their use of agarrar is qualitatively distinct, as seen by their co-occurrence with different semantic types of complements, visualized by the bar graph in Fig. 2. In the Texas corpus, agarrar takes an abstract NP, such as an achievement or a benefit, over $6 \circ \%$ of the time (agarré crédito 'I got credit', agarrar experiencia 'to get experience'). In comparison, less than $20 \%$ of the ACTIV-ES 
Mexican agarrar tokens take an abstract complement. More often, agarrar in the Mexican subtitle corpus is used to connote a physical grasp, such as with people or physical objects (agarramos el portafolio 'we grabbed the briefcase'). A Fisher's exact test reveals the difference between the distribution of complement categories to be highly significant ( $p$-value $<2.2 \mathrm{e}-16$ ) and the Cramér's V value of 0.502 indicates a strong association. This confirms that the corpora are different with respect to the use of agarrar even though it occurs with similar frequency in Texas and Mexico. In the Spanish of Texas, the verb is used with a different type of complement than it is in its source variety of Mexico.

The results of the multifactorial logistic regression models of the use of agarrar versus a competitor (see Appendix 1) show that when comparing models containing social and linguistic predictor variables, the highest performing model (the one with the lowest AIC score) contained the predictor variables Regional Survey Point + Physical Grasp + Self Report of Spanish Writing Ability + Country of Birth + M-index. Birth was modeled as a categorical variable (Argentina, Colombia, Mexico, USA, etc.) and as a binary variable (born within the U.S. and born outside of the U.S.). The binary variable was chosen in the final model due to its superior predictive power. The effects of these predictor variables are visualized in the graphs in Fig. 3. The social variables that increase a speaker's likelihood of using agarrar are (i) residing in the El Paso region relative to the other survey regions, (ii) having a low self-rated Spanish writing ability, and (iii) being born in the U.S. Also increasing the likelihood of using agarrar is its co-occurrence with a non-abstract complement, (e.g., agarrar una gallina 'grab a chicken'), which indicates that the verb is still the one that is primarily used to express a sense of grabbing, grasping, or clutching in this dataset in addition to its use in constructions with abstract complements.

\section{5}

\section{Discussion}

The findings allow us to offer responses to our research questions. First, with regard to whether the use of the verb agarrar is increased in general in the bilingual corpus as compared to other Spanish varieties, the answer appears to be negative. The effect size of the differences we find between corpora is small, probably because there are so few tokens of agarrar in relation to the size of the corpora. With few observations distributed within a large corpus, the likelihood of randomly selecting a token of agarrar from any of the sub-corpora remains similarly low across the board. Despite the lack of a meaningful effect size in the frequency of agarrar between corpora, we know from the 


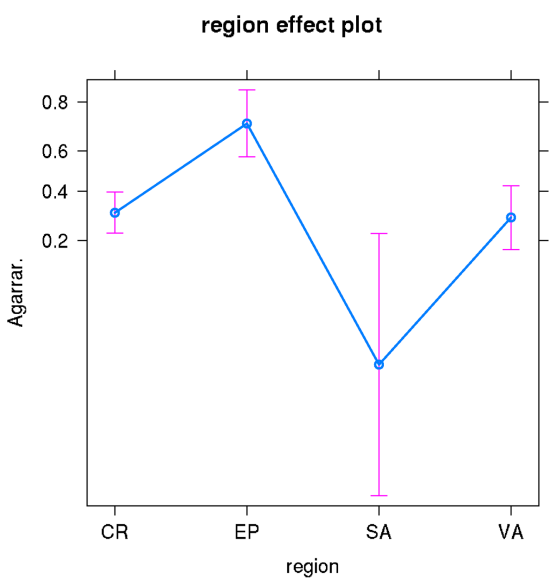

spanish_ability_writing effect plot

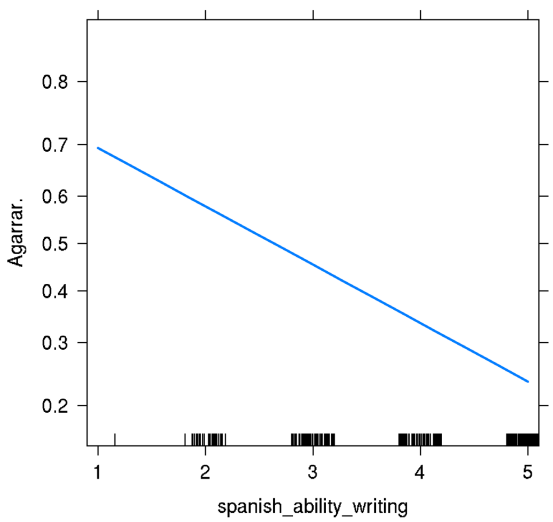

Physical.Grasp effect plot

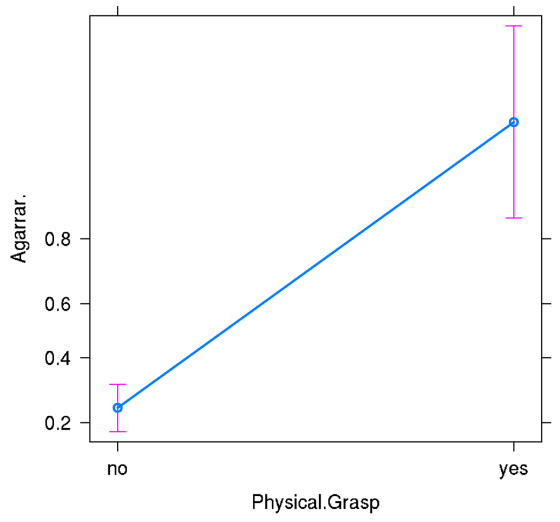

US_born effect plot

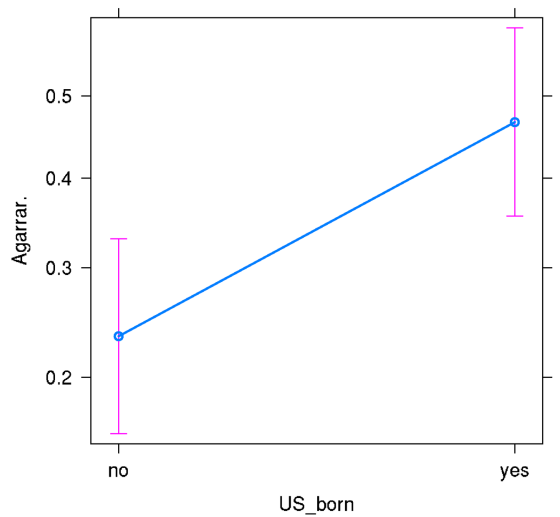

FIGURE 3 Factors that predict the selection of \{agarrar $\}$

descriptive data that the Spanish varieties of Texas and Mexico are more similar to one another than they are to any of the other Spanish language varieties surveyed and that their token counts of agarrar range from $35 \%$ to $80 \%$ more than than the other corpora. In other words, the verb agarrar is used more often in Texas and Mexico than it is in other regions.

While agarrar is used with similar rates in Texas and Mexico, we found, in answer to our second research question, that the agarrar+NP expressions in the Spanish in Texas corpus are qualitatively different from those evidenced in its Mexican source and that this difference is significant. Specifically, the majority of the agarrar+NP constructions attested in Spanish in Texas occurred with an abstract complement unlike in ACTIV-ES Mexico, where the complements overwhelmingly remained ones that would be expected for the core meaning of the lexical verb, 'grasp'. This suggests that the meaning of agarrar in the U.S. 
Spanish variety has become generalized along the lines of English get and is now available for use as a support verb in specific collocations. Moreover, its use as a support verb appears to converge with the English light verb in the type of complement it selects. Both get and agarrar as svc s occur most often with abstract NPs. Additionally, in both languages, the get/agarrar constructions tend to denote the conferral of services, opportunities, or rewards upon the subject (Molina Plaza, 2015).

As noted in the introduction, the unconventional usage of agarrar that is witnessed in Texas (and attested in other contact regions of the U.S. Southwest) creates a novel grammatical frame for this verb. When agarrar is used in these support verb constructions, the thematic role of its grammatical subject is that of beneficiary or experiencer. It is a copy of the thematic structure of similar English svC s with get. This is significant because there is a productive pattern to the extended use of agarrar; it is not limited to a single calqued expression. This confirms the view of Backus and Dorleijn (2009) that loan translations can impact the grammar of the recipient language, in this case by introducing new possibilities for thematic mappings with agarrar based on the pattern of English (Matras and Sakel, 2007).

That agarrar is used in unconventional constructions in the Spanish in Texas Corpus but not in the Mexican ACTIV-Es subtitle corpus indicates that the structures meet the criteria to be considered contact-induced: they behave like similar expressions in the putative source variety, American English, but they differ qualitatively from those found in the recipient language (Thomason, 2001; Poplack and Levey, 2010). This lends credence to the idea that agarré trabajo and agarré crédito in the Spanish in Texas Corpus are calques of the English constructions I got a job and I got credit, as suggested by Sayer (2008) and Cárdenas (1982) for U.S. Spanish. That these constructions can be calqued on the spot, rather than acquired through other recipient language speakers may be evidenced by a mixed language example from the corpus, agarré Most Shy, which is used in a very specialized sense to mean that the speaker was recognized by her peers, usually by means of a vote, as the most timid individual in her high school graduating class.

Our final research question concerned the linguistic and external factors that predicted the enhanced use of agarrar relative to its alternatives, such as recibir, obtener, conseguir, in the bilingual corpus. The sole linguistic factor that increased the odds that a speaker would choose agarrar relative to the other verbs is having a complement that can be physically grasped. So, in addition to its extended use in support verb constructions in Spanish in Texas, agarrar is still used to express its specific, core lexical meaning and there is no evidence that the sense of grasping could be alternately denoted by recibir, obtener, or 
conseguir. The external factors that predict an augmented use of agarrar tell us that those who are born in the U.S. rather than in another country tend to use agarrar at higher rates. Additionally, there is an inverse correlation between speakers rating themselves highly in Spanish writing ability and their agarrar use. In other words, the worse speakers rate their writing in Spanish, the more likely they are to use agarrar. These factors combined suggest that higher degrees of contact with English have a stronger influence on the extended use of agarrar. These results are consistent with the criterion used by Mougeon et al. (2005) for detecting contact-induced variations in French in majority anglophone towns of Ontario.

Our findings also demonstrated a potential regional effect: those who live in El Paso express higher rates of agarrar relative to the cities of Texas to the east. Unfortunately, El Paso is the survey point with a single interviewer, so it is impossible to know whether this is truly characteristic of the El Paso region. The increased rate of agarrar observed among the El Paso speakers may reflect the usage of a community of practice (i.e., the interviewer's social network) rather than the region. Whichever the case, this result bolsters the notion that contact-induced expressions like agarrar+NP may be restricted to a region or, potentially, conventionalized by a community of practice, as would be predicted by Backus and Dorleijn (2009) for loan translations and by Sebba (2009) for bilingual phenomena more generally. In contrast, structural transfer, which is not limited to specific expressions, but occurs if its structural environment is met, should be observable whenever the same language pairings are in contact. For instance, inversion in embedded clauses in Spanish-English contact is widespread, irrespective of the pre-contact Spanish or English varieties (e.g, I don't know what is his name).

We have presented linguistic arguments and empirical evidence for categorizing the unconventional agarrar+NP construction found in the Spanish in Texas Corpus as a loan translation that is calqued on a similar expression in English. Our quantitative evidence is based on comparing word frequency and the semantics of the NP complement across corpora and on considering the linguistic and external factors that lead to the selection of agarrar over its potential alternatives. We find strong evidence that the unconventional agarrar $+\mathrm{NP}$ expressions are qualitatively innovative with respect to non-contact varieties and that increased rates of agarrar occur in the speech of Texas Spanish speakers who have greater contact with English. We also find that agarrar is used at 
similar rates in the Texas and Mexican corpora, albeit in very different semantic contexts. Thus, in Texas, agarrar is used as a loan transfer, extended beyond its usage in Mexico. One question that we cannot answer directly from our data is why agarrar, rather than a semantic competitor verb like conseguir or tomar, is used as a collocate in these loan translation constructions. Our word frequency comparisons might be enlightening in this regard. We surmise that it is likely that agarrar was selected as the calque for the English to get because Mexican Spanish, which is highly influential in the Spanish spoken in Texas, already has a highly productive use of agarrar (in the conventional sense) relative to other Spanish varieties.

There are two implications of this study that warrant further study. First, specific loan translations may be salient in a corpus, but they might not be frequent. This can be problematic for conducting frequency comparisons across large corpora because the magnitude of effect sizes is likely to always be low. Scholars agree that quantitative cross-corpus comparison is a mainstay of empirical studies of language contact, but its results may be misleading in practice. This means that we must find different ways to model putative features of transfer across bilingual corpora. Secondly, our findings indicate that, in replicating the grammatical patterns of the source language (Matras and Sakel, 2007), loan translations can qualitatively affect the grammar as well as the lexicon (Backus and Dorleijn, 2009).

\section{References}

Backus, Ad and Margreet Dorleijn. 20og. Loan translations versus code-switching. In Barbara E. Bullock and Almeida Jacqueline Toribio (eds.), The Cambridge Handbook of Linguistic Code-Switching, 75-93. Cambridge, UK: Cambridge University Press.

Barnett, Ruthanna, Eva Codó, Eva Eppler, Montse Forcadell, Penelope GardnerChloros, Roeland van Hout, Melissa Moyer, et al. 20oo. The Lid Es Coding Manual A document for preparing and analyzing language interaction data Version 1.1-July, 1999. International Journal of Bilingualism 4, 2: 131-32.

Biber, Douglas, Stig Johansson, Geoffrey Leech, Susan Conrad, and Edward Finegan. 1999. Longman Grammar of Spoken and Written English. New York: Longman Publications Group.

Brysbaert, M. and B. New. 20og. Subtlexus: American Word Frequencies. http:// subtlexus.lexique.org/ (accessed March 12, 2017).

Bullock, Barbara E. and Almeida Jacqueline Toribio. 2012. The Spanish in Texas Corpus Project. COERLL: The University of Texas at Austin. http://www.spanishintexas. org/. 
Butt, Miriam. 2004. The light verb jungle. In Gulsat Aygen, Claire Bowern and Conor Quinn (eds.), Harvard Working Papers in Linguistics, 1-49. Boston: Harvard Working Papers in Linguistics, Vol. 9 .

Butt, Miriam. 2010. The light verb jungle: Still hacking away. In Amberber Menigustu, Brett Baker, and Mark Harvey (eds.), Complex Predicates: Cross-Linguistic Perspectives on Event Structure, 48-78. Cambridge: Cambridge University Press, 2010.

Cárdenas, Daniel N. 1982. Morphosyntactic preferences in the Spanish of southern California. Word 33: 29-40.

Coe, Robert. 2002. It's the effect size, stupid:What effect size is and why it is important," http://www.leeds.ac.uk/educol/documents/oooo2182.htm. Accessed March 11, 2017.

Cohen, Jacob. 2013. Statistical Power Analysis for the Behavioral Sciences, 2nd ed. Hoboken: Taylor and Francis.

Davies, Mark. 2002. Corpus Del Español: 100 Million Words, 1200s-19oos. http://www. corpusdelespanol.org.

Dubois, Sylvie, and Sibylle Noetzel. 2005. Intergenerational pattern of interference and internally-motivated changes in Cajun French. Bilingualism 8: 131-43.

Edwards, Malcolm, and Penelope Gardner-Chloros. 2007. Compound verbs in codeswitching: Bilinguals making do? International Journal of Bilingualism 11: 73-91.

Francom, Jerid, Mans Hulden, and Adam Ussishkin. 2014. ACTIV-ES: A comparable, cross-dialect corpus of 'everyday' Spanish from Argentina, Mexico, and Spain." In LREC, 2014, 1733-37.

Francom, Jerid, Amy LaCross, and Adam Ussishkin. 2010. How specialized are specialized corpora? Behavioral evaluation of corpus representativeness for Maltese." In LREC, 2010, 421-427.

Jespersen, Otto. 1954 A Modern English Grammar on Historical Principles, Part VI, Morphology. London: George Allen and Unwin Ltd.

Kearns, Kate. 2002. Lightverbs in English. Citeseer. doi:10.1.1.132.29\&rep=rep1\&type=pdf.

Kilgarriff, Adam. 2001. Comparing corpora. International Journal of Corpus Linguistics 6: $97-133$.

Labov, William. 1972. Sociolinguistic Patterns. Philadelphia: University of Pennsylvania Press.

Laufer, Batia, and Tina Waldman. 2011. Verb-noun collocations in second language writing: A corpus analysis of learners' English. Language Learning 61: 647-72.

Matras, Yaron, and Jeanette Sakel. 2007. Grammatical borrowing in cross-linguistic perspective. Walter de Gruyter.

Mel'čuk, Igor. 2012. Phraseology in the language, in the dictionary, and in the computer." Yearbook of Phraseology 3: 31-56.

Mel'čuk, Igor A. 2004. Verbes supports sans peine. Lingvisticae Investigationes 27: 203-17. 
Molina Plaza, Silvia. 2015. Contrastive analysis of stretched collocations with get and take: Their use and pedagogical implications. Journal of Social Sciences 11: 179.

Mougeon, Raymond, Terry Nadasdi, and Katherine Rehner. 2005. Contact-induced linguistic innovations on the continuum of language use: The case of French in Ontario. Bilingualism: Language and Cognition 8: 99-115.

Muysken, Pieter. 2000. Bilingual Speech: A Typology of Code-Mixing. Cambridge: Cambridge University Press.

Olsen,Julie. 2014. Losverbos de apoyo enespañol:estudio de pillar, agarrar, cogerytomar. The Artic University of Norway. http://www.ub.uit.no/munin/handle/10037/ 6580 .

Otheguy, Ricardo. 1993 A reconsideration of the notion of loan translation in the analysis of U.S. Spanish. In Ana Roca and John M. Lipski (eds.), Spanish in the United States: Linguistic Contact and Diversity, 21-45. Berlin: Mouton de Gruyter.

Otheguy, Ricardo, and Ana Celia Zentella. 2012. Spanish in New York: Language Contact, Dialectal Leveling, and Structural Continuity. Oxford Studies in Sociolinguistics. New York: Oxford University Press.

Poplack, Shana, and Stephen Levey. 2010. Contact-induced grammatical change: a cautionary tale. Language and Space: An International Handbook of Linguistic Variation 1: 391-419.

Poplack, Shana, Lauren Zentz, and Nathalie Dion. 2012. Phrase-final prepositions in Quebec French: an empirical study of contact, code-switching and resistance to convergence. Bilingualism: Language and Cognition 15: 203-25.

Romaine, Suzanne. 1986. The syntax and semantics of the code-mixed compound verb in Panjabi/English bilingual discourse. In Languages and Linguistics: The Interdependence of Theory, Data, and Application, 35-49. Georgetown University Round Table on Languages and Linguistics.

Salido, Marcos Garcia. 2016. Error analysis of support verb constructions in written Spanish learner corpora. The Modern Language Journal 10o: 362-76.

Sánchez, Rosaura. 1972. Nuestra circunstancia linguistica. El Grito: A Journal of Contemporary Mexican-American Thought 6: 45-74.

Sánchez, Rosaura. 1982. Our linguistic and social context. In Jon Amastae and L. Elías-Olivares (eds.), Spanish in the United States: Sociolinguistic Aspects, 9-46. Cambridge, UK: Cambridge University Press.

Sánchez, Rosaura. 1994. Chicano Discourse: Socio-historical Perspectives. Houston, TX: Arte Público Press.

Sayer, Peter. 2008. Demystifying language mixing: Spanglish in school. Journal of Latinos and Education 7: 94-112. 
Sebba, Mark. 2009. On the notions of congruence and convergence in code-switching. In Barbara E. Bullock and Almeida Jacqueline Toribio (eds.), The Cambridge Handbook of Linguistic Code-Switching, 40-57. Cambridge University Press.

Silva-Corvalán, Carmen. 1994. Language Contact and Change: Spanish in Los Angeles. Oxford Studies in Language Contact. Oxford: Clarendon.

Sitaram, Sunayana, and Alan W. Black. 2016. Speech synthesis of code mixed text. LREC, 2016: 3422-28.

Thomason, Sarah G. 2001. Language Contact: An Introduction. Washington, D.C.: Georgetown University Press.

Toribio, Almeida Jaqueline, and Barbara E. Bullock. 2016. A new look at heritage Spanish and its speakers. In D. Pascual y Cabo (ed.), Advances in Spanish as a Heritage Language, 27-50. New York: John Benjamins.

Travis, Catherine E., and Rena Torres Cacoullos. 2013. Making voices count: Corpus compilation in bilingual communities. Australian Journal of Linguistics 33:170-94.

Treffers-Daller, Jeanine. 2011. Grammatical collocations and verb-particle constructions in Brussels French: A corpus-linguistic approach to transfer. International Journal of Bilingualism 16: 53-82.

Wasserscheidt, Philipp. 2016. Construction grammar and code-mixing. In Monika Reif and Justyna A. Robinson (eds.), Cognitive Perspectives on Bilingualism, 17: 65-9o. Berlin: Walter de Gruyter.

Wierzbicka, Anna. 1982. Why can you have a drink when you can't have an eat? Language 58: 753-99.

Zenner, Eline, Dirk Speelman, and Dirk Geeraerts. 2012. Cognitive sociolinguistics meets loanword research: measuring variation in the success of anglicisms in Dutch. Cognitive Linguistics 23: 749-92.

\section{Appendix 1}

Best Model Fit

\begin{tabular}{lcccl}
\hline & Estimate & Std. Error & $z$ value & $\operatorname{Pr}(>|z|)$ \\
\hline (Intercept) & 0.83998 & 2.10040 & 0.400 & 0.6892 \\
RegionEP & 1.75668 & 0.40268 & 4.363 & $1.29 \mathrm{e}-05^{* * *}$ \\
RegionSA & -3.28480 & 1.37838 & -2.383 & $0.0172 *$ \\
RegionVA & -0.06013 & 0.37901 & -0.159 & 0.8739 \\
Physical Grasp & 4.22655 & 0.78207 & 5.404 & $6.51 \mathrm{e}-\mathrm{o} 8$ *** \\
Spanish writing ability & -0.58328 & 0.42290 & -1.379 & 0.1678
\end{tabular}


Appendix 1 Cont.

\begin{tabular}{lcccl}
\hline & Estimate & Std. Error & $z$ value & \multicolumn{1}{c}{$\operatorname{Pr}(>|z|)$} \\
\hline US born & 1.29768 & 0.33193 & 3.909 & $9.25 \mathrm{e}^{-0} 5^{* * *}$ \\
M-index & 3.46846 & 2.57588 & 1.347 & 0.1781 \\
Null deviance: 403.97 on 306 degrees of freedom & & \\
Residual deviance: 279.24 on 299 degrees of freedom & \\
AIC: 295.24 & & \\
\end{tabular}

